\title{
0 ensino remoto na Educação Infantil: desafios e possibilidades no uso dos recursos tecnológicos
}

\author{
Remote teaching in Childhood Education: challenges and possibilities \\ in the use of technological resources
}

\section{Enseñanza a distancia en Educación Infantil: retos y posibilidades en el uso de recursos tecnológicos}

Francimara de Sousa Cunha1; Enia Maria Ferst²; Nilra Jane Filgueira Bezerra ${ }^{3}$

\section{RESUMO}

O presente artigo trata a educação não presencial em tempos de pandemia da Covid-19, relacionando-a com o uso das tecnologias digitais como ferramentas de apoio pedagógico e didático diante das dificuldades existentes neste momento tão desafiador com o novo formato de aulas remotas. Nesse sentido, o presente estudo foi realizado com o objetivo de analisar e compreender a realidade que envolve os principais aspectos relativos às contribuições e desafios das mídias e dos recursos tecnológicos na Educação Infantil, tendo como público-alvo os profissionais e alunos dessa etapa de ensino. A pesquisa foi realizada em duas escolas de Educação Infantil no Município de Rorainópolis, com o intuito de acompanhar, observar e analisar os processos de desenvolvimentos das aulas em relação as medidas estratégicas realizadas para a socialização e interação das turmas, bem como perceber quais recursos são utilizados, e como acontece esse vínculo entre a escola, família e aluno nesse novo contexto educacional. Realizou-se ainda uma coleta de informações através de entrevistas realizadas com seis professores e seis pais de alunos. Ao fim deste estudo foi possível concluir que o ensino remoto tem sido bastante desafiador e não possui um êxito considerado bom, tanto por ser algo novo para os profissionais de ensino que estão trabalhando em casa, quanto para os pais e familiares das crianças, pela falta de preparo e tempo para acompanhar os filhos, que precisam ser auxiliados e mediados com paciência, atenção e dedicação.

Palavras-chave: Aulas-remotas; COVID-19; Educação Infantil; Tecnologias.

\begin{abstract}
This article deals with non-face-to-face education in times of Covid-19 pandemic, relating it to the use of digital technologies as tools for pedagogical and didactic support in the face of the existing difficulties in this very challenging moment with the new format of remote classes. In this sense, the present study was carried out with the objective of analyzing and understanding the reality that involves the main aspects related to the contributions and challenges of the media and technological resources in Early Childhood Education, having as target audience the professionals and students of this stage of teaching. The research was carried out in two schools of Early Childhood Education in the Municipality of Rorainópolis, with the aim of monitoring, observing and analyzing the development processes of the classes in relation to the strategic measures taken for the socialization and interaction of the classes, as well as realizing what resources are used, and how this link
\end{abstract}

\footnotetext{
${ }^{1}$ Mestranda em Educação pelo Programa de Pós-Graduação em Educação (PPGE) Universidade Estadual de Roraima (UERR) em Parceria com Instituto Federal de Roraima (IFRR), Boa Vista/RR - Brasil. E-mail: francimara.cunha@uerr.edu.br

${ }^{2}$ Doutora em Educação em Ciências e Matemática e professora do Programa de Pós-graduação em Ensino de Ciências da Universidade Estadual de Roraima (UERR), Boa Vista/RR - Brasil. E-mail: mestreenia@gmail.com

${ }^{3}$ Doutora em Educação em Ensino de Ciência e Matemática e Professora do Instituto Federal de Educação, Ciência e Tecnologia de Roraima (IFRR), Boa Vista/RR - Brasil. E-mail: nilrajane@ifrr.edu.br
} 
between school, family and student happens in this new educational context. Information was also collected through interviews with six teachers and six parents of students. At the end of this study, it was possible to conclude that remote education has been quite challenging and does not have a success considered good, both because it is something new for teaching professionals who are working at home, and for parents and family of children, due to the lack of preparation and time to accompany the children, who need to be helped and mediated with patience, attention and dedication.

Keywords: Remote lessons; COVID-19; Child education; Technologies.

\section{RESUMEN}

Este artículo trata sobre la educación no presencial en tiempos de la pandemia Covid-19, relacionándola con el uso de tecnologías digitales como herramientas de apoyo pedagógico y didáctico ante las dificultades existentes en este momento tan desafiante con las nuevas formato de clases remotas. En este sentido, el presente estudio se realizó con el objetivo de analizar y comprender la realidad que involucra los principales aspectos relacionados con los aportes y desafíos de los medios de comunicación y los recursos tecnológicos en la Educación Infantil, teniendo como público objetivo a los profesionales y estudiantes de esta etapa de enseñanza. La investigación se realizó en dos escuelas de Educación Infantil del Municipio de Rorainópolis, con el objetivo de monitorear, observar y analizar los procesos de desarrollo de las clases en relación a las medidas estratégicas tomadas para la socialización e interacción de las clases, como, así como darse cuenta de qué recursos se utilizan, y cómo se da este vínculo entre escuela, familia y alumno en este nuevo contexto educativo. También se recopiló información a través de entrevistas con seis profesores y seis padres de alumnos. Al final de este estudio se pudo concluir que la educación a distancia ha sido bastante desafiante y no tiene un éxito considerado bueno, tanto porque es algo nuevo para los profesionales de la enseñanza que se encuentran trabajando en casa, como para los padres y familiares de los niños, por la falta de preparación y tiempo para acompañar a los niños, quienes necesitan ser ayudados y mediatizados con paciencia, atención y dedicación.

Palabras clave: Clases remotas; COVID-19; Educación Infantil; Tecnologías.

\section{INTRODUÇÃO}

Estamos atravessando um momento em que as práticas educativas vem passando por alterações repentinas e também desafiadoras, e diante do atual contexto de pandemia do covid-19 envolvendo principalmente a rotina escolar se tornou eminente a necessidade de se adaptar a essa nova realidade. A forma de ensinar mudou, não se pode ir mais a escola como de costume, e o quadro se agrava quando percebemos que a maioria das pessoas não estavam totalmente preparadas para estas adequações e transformações. Porém, não podemos simplesmente nos manter passivos e assistir a essas mudanças sem participar ativamente delas. Não é fácil, mas neste momento de pandemia o qual estamos vivenciando, é visto que há uma real necessidade de adequação diante do atual processo de educação em formato de aulas não presenciais, pois é necessário quebrar estes paradigmas e, às pressas, reinventar e reforçar a inter-relação da educação: a escola, o aluno e a família. A cerca dessa questão, Moram (2013, p. 12), tece o seguinte comentário:

[...] enquanto a sociedade muda e experimenta desafios mais complexos, a educação formal continua, de maneira geral, organizada de modo previsível, repetitivo, burocrático, pouco atraente. Apesar das teorias avançadas, predomina, na prática, uma visão conservadora, repetindo o que está consolidado, o que não oferece risco nem grandes tensões.

Diante do atual momento de distanciamento social as escolas têm se adaptado às dificuldades e aos desafios educacionais, buscando soluções de enfrentamento às dificuldades e visando contribuir de forma estratégica para o ensino através de aulas remotas - o que vem se tornando cada vez mais 
importante para a redução dos efeitos negativos do distanciamento temporário - porém, há evidências indicando que lacunas poderão ser criadas caso demore o retorno do método de ensino presencial.

Muitas escolas, independentemente de serem de ensino infantil ou não, têm aproveitado o difícil cenário para desenvolver novas metodologias - como o uso de tecnologias digitais - bem como para se aprofundar nas já existentes. Diante disto, surge o questionamento: Como isso funcionará diante de uma realidade analógica como a de Roraima e de Rorainópolis?

O maior desafio ainda é a busca por uma metodologia voltada para um ensino produtivo e motivador. Essa é uma meta que recai principalmente sobre os educadores, mas também exige grande responsabilidade da família, que está acompanhando de perto todo esse processo. Como adaptar os conteúdos e as dinâmicas de sala de aula que agora terão de ocorrer em casa e em conjunto com a família? Como não prejudicar o processo de aprendizagem? Como manter os alunos interessados e engajados nas aulas não presenciais? A tarefa é ainda mais complexa para aqueles que atuam em áreas distantes da tecnologia ou que lecionam na educação infantil.

Baseado no índice de participação dos discentes nas atividades remotas, e nas dificuldades de adaptação dos professores que dependem também de recursos acessíveis e materiais manipuláveis para a sua prática, é sabido que essas novas formas de levar a escola (e os conteúdos) até o aluno estão sendo desafiadoras para todos os envolvidos. Ou seja, tanto para os professores que em tempo recorde tiveram que reinventar o seu plano de aula, se aventurando em um universo desconhecido para muitos, adaptando a forma de ensino e se utilizando de novas tecnologias; quanto para os responsáveis, que em meio a um turbilhão de atividades e preocupações, estão assumindo o papel de tutores e educadores das crianças. Há ainda a dificuldade de contato e localização dos responsáveis, o risco de contágio durante a troca de materiais, apostilas e livros, além da falta de acesso a aparelhos eletrônicos como celulares e computadores.

Uma vez que os estudantes estão supostamente confinados em suas casas, se escancara outro problema: a desigualdade social, que interfere diretamente na qualidade de vida, com o acesso (ou não) às condições básicas como alimentação adequada, energia elétrica, saneamento básico, etc. Podemos ainda mencionar o clima doméstico, por vezes, marcado por violências e a não estrutura para manter as rotinas escolares, como um espaço adequado para os estudos. Importante ainda sublinhar que muitos pais se sentem incapazes em auxiliar seus filhos, seja por uma questão de limitações de conhecimento e informação (em relação ao conteúdo escolar e a habilidade para lidar com os recursos digitais) ou por uma questão de condição existencial. (Jornal Pensar a Educação em Pauta, Ano 9-No 311).

O modelo metodológico que rege as aulas nas escolas, onde é realizado o estudo exploratório desta pesquisa, é fundamentado nas diretrizes dos cinco campos de experiência da Base Nacional Comum Curricular (BNCC) que são: Eu, o outro e o nós, Corpo, gestos e movimentos. Traços, sons, cores e formas. Escuta, fala, pensamento e imaginação. Espaço, tempo, quantidades, relações e transformações, que foi aprovada em dezembro de 2017 e começou a ser colocada em prática em todos os espaços e salas de aula da Educação Infantil e do Ensino Fundamental a partir de 2020, para orientar os educandos nos conteúdos e objetivos de aprendizagem; além de também realizar uma busca ativa da participação dos estudantes.

O formato desse novo contexto de escola digital apesar de trazer muitos desafios, também tem proporcionado possibilidades de aprendizagem dos envolvidos, com a continuidade do processo de 
ensino das aulas não presenciais. E assim trazendo a família para uma participação mais ativa no desenvolvimento estudantil dos filhos.

\section{AS AULAS NÃO PRESENCIAIS NA EDUCAÇÃO INFANTIL: UM MOMENTO DESAFIADOR}

A Lei de Diretrizes e Bases da Educação Nacional, n. 9.394/96, promulgada em dezembro de 1996, estabelece de forma incisiva o vínculo entre o atendimento às crianças de zero a seis anos e a educação. Com o surgimento do novo Coronavírus e das consequentes medidas de isolamento social, implementou-se o decreto Municipal de Rorainópolis no 051/2020, que suspendeu as aulas presenciais a partir do dia 17 de março de 2020. Dessa forma, as crianças precisaram se adaptar à nova rotina de estudos em um ambiente diferente do qual elas estavam acostumadas, ou seja, passaram a ficar em casa nos horários que eram de costumes irem à escola, não podem mais ver e abraçar a professora(a) e os coleguinhas a não ser de forma digital, começaram a usar máscaras sem muito entender o real motivo, tiveram que aprender a se comunicar com mais frequência através de áudios ou vídeos, enfim muitas mudanças aconteceram com muita rapidez, o que pode gerar grande estranhamento para os envolvidos só processo. Por outro lado, os professores precisaram adequar os planos de aulas e as maneiras de fazer com que as atividades e conteúdos cheguem aos alunos.

Com o aprimoramento das aulas remotas, as escolas também se viram desafiadas em relação a esta nova prática. Tendo que se reinventar e buscar estratégias de ensino, e ao mesmo tempo adaptandose as realidades incorporadas no contexto educacional e suas vivências, buscando a parceria com os pais e responsáveis, o que vem a ser vital para continuação do processo educacional e fazer com que o ensino não presencial funcione. Desse modo, torna- se ainda mais clara a extrema importância da família e o elo desta para com a escola, com garantia na participação das crianças, e assim para que realizem as atividades com dedicação e colaboração nas aulas.

O fechamento das escolas por causa da pandemia do Coronavírus trouxe um desafio para a Educação Infantil: Como as aulas não presenciais terão continuidade diante da realidade de locais como Roraima e de Rorainópolis? Quais os pontos positivos e negativos dentro desse novo contexto de ensino diante das dificuldades ligadas ao uso das tecnologias digitais como recurso metodológico para as aulas remotas?

Diante desses questionamentos citados, e das afirmações em relação a entrevista, nos deparamos com inúmeros outros desafios como a falta de uma rede de internet de qualidade, o não acesso à ambientes públicos (mesmo que por ordem de agendamento para o acesso), a falta de ferramentas como um celular ou um notebook, a falta de capacitação de alguns professores para lidar com essas tecnologias, o difícil acesso aos alunos que moram em zonas rurais e também o despreparo das famílias em relação a aparelhos tecnológicos.

Com a decisão de suspender as aulas presenciais em março de 2020, por meio da Portaria Federal da Educação no 343, o Ministério da Educação (MEC) se manifestou sobre a substituição das aulas presenciais por aulas remotas, enquanto durar a pandemia da Covid-19. Posteriormente, tal portaria recebeu ajustes e acréscimos através das portarias 345 e 356/2020 entre 11 e 23 de março. Desde então, cada estado e município teve de se organizar para oferecer atividades remotas: aulas mediadas por conteúdos produzidos e disponibilizado online, acompanhado das aulas virtuais ministradas em tempo real pelo professor responsável por aquela disciplina aos estudantes. (PROPOSTA DE PARECER 
Apesar dos esforços para que o ensino tenha continuidade, tanto por parte dos docentes quanto dos discentes, destacamos ainda a preocupação dos educadores em relação ao tempo de exposição das crianças às telas. Outra situação a ser superada é a disponibilidade dos pais. Os mesmos relatam não ter muito tempo para acompanhar os filhos nesse novo contexto de ensino, pois a maioria afirma que trabalham nos horários das aulas ao vivo, porém sempre que podem tentam acompanhar depois na realização das atividades. O primeiro desafio está aos poucos sendo vencido, mesmo com algumas dificuldades relacionadas ao uso das tecnologias a favor do conhecimento, através dos esforços e das adequações dos educadores. Já a segunda questão, relativa ao tempo disponível dos pais, depende de muitas variáveis, e, por conseguinte, é mais complexa de solucionar.

Devemos lembrar que a presença da família é um fator de grande importância para que se possam desenvolver as atividades pedagógicas, principalmente neste período de pandemia e distanciamento social, por estarem mais presentes nas vivências escolares dos filhos. Podendo assim colaborar mais de perto no processo de ensino e aprendizagem em períodos das aulas remotas. Auxiliando os mesmos no desenvolvimento de suas autonomias e habilidades cognitivas. Não é fácil adaptar-se a este novo método de ensino, no entanto, a pandemia acarretou esta necessidade. Nesse momento, o empenho e a dedicação de todos têm sido os melhores aliados na escolarização dos pequenos.

As diversas mudanças e adequações realizadas com tanta agilidade tornou praticamente impossível a não existência de transtornos como as demandas que envolvem o mundo virtual e o processo de ensino e aprendizagem nos âmbitos da Educação Infantil, que surgiram as problemáticas acerca de se o docente tem utilizado as mídias e os recursos tecnológicos em suas práticas pedagógicas nas aulas, e, em caso afirmativo, como ele tem trabalhado com as novas aprendizagens adquiridas por seus alunos no mundo midiático. O que demanda grande dedicação por parte de todos os envolvidos: escola, professores e pais ou responsáveis, pois ao interagir nesse mundo de diversidade cibernética, a criança tem acesso a um infinito número de possibilidades e novos modos de perceber a realidade, de aprender, de produzir e difundir conhecimentos e informações.

\section{COMO MANTER O VÍNCULO ENTRE ESCOLA E FAMÍLIA EM TEMPOS DE PANDEMIA?}

A relação professor-aluno é muito diferente da relação pai-filho. Além disso, é perceptível que os familiares ou responsáveis não estão sentindo-se preparados para lidar com os conteúdos e rotinas escolares, ainda mais quando se trata em auxiliar e acompanhar os filhos nas realizações das aulas e atividades. No entanto, diante do que foi avaliado na entrevista realizada com os pais e professores, foi observado que muitos dos pais estão angustiados e se sentindo pressionados pelo compromisso que os tomam seu tempo, e sua maior dedicação para com os filhos. Além disso, o tempo que a criança tem disponível para o ensino remoto é diferente do tempo na escola. Não apenas por questões de estrutura, mas porque o ambiente e nível de atenção também mudam.

O mundo vem passando por várias transformações ao longo dos anos, é visto que ultimamente estas transformações estão acontecendo em curtos períodos de tempo. O cenário educacional também passa por constantes mudanças, como por exemplo as plataformas midiáticas têm atuado de forma permanente e cotidiana na vida das crianças que compõem o cenário da Educação Infantil, socializando-as paralelamente às instituições de ensino, podendo, assim, ampliar as suas habilidades 
e visão de mundo. Nesse sentido, muitos são os questionamentos quanto à práxis pedagógica para atender a essa nova geração. Percebemos que muitos profissionais ainda precisam ter em mente que é necessário acompanhar essas metamorfoses, é preciso inovar e se reinventar diante das práticas e ações mediadas pela tecnologia que possam contribuir de alguma forma para o processo de ensino /aprendizagem em diversos contextos históricos, pois este é um exercício necessário para uma prática permanentemente transformadora. Porém existem também aqueles profissionais que têm se desdobrado para aprender a trabalhar com novas ferramentas, mas não só eles: estudantes, pais e familiares também estão se adequando às novas dinâmicas.

Levando esse contexto para as escolas de Ensino Infantil onde foi realizada uma entrevista com os pais e professores a respeito do ensino em tempos de pandemia, com aquisição de informações de que, as escolas estudadas estão produzindo o seu próprio material, ou seja, o "caderno de interatividade", planejado, organizado e montado pelos professores juntamente com os coordenadores das escolas em pauta , contando ainda com a participação e com um olhar mais aprofundado da equipe de coordenadores e supervisores da Secretaria Municipal de Educação Rorainópolis - SEMED, onde estes cadernos são avaliados e validados, de acordo com o nível de cada modalidade de ensino, e em seguida deliberam as impressões e confecções dos mesmos na escola e assim para a disponibilidade dos pais ou responsáveis de ir buscar na escola.

Estes cadernos de interatividades possuem o conteúdo disponível de forma impressa na escola e são também aplicados e acompanhados pelo grupo de WhatsApp criado para atendimento da turma. Onde cada professor(a) é responsável por criar a metodologia da sua aula, porém, tendo que utilizar o mesmo conteúdo. O caderno interativo direcionado a educação infantil possui um conteúdo mais ilustrativo e lúdico, com muitas figuras, desenhos coloridos e algumas solicitações de registros de acordo com a assimilação, compreensão e habilidade de cada série. As interações são feitas todos os dias em um determinado horário de aula, onde os alunos interagem uns com os outros e com o seu (a) professor(a), através de áudios, vídeos e fotos, registrando sua participação e socialização dos conteúdos trabalhados.

É por meio da interação e intermediação desses cadernos de interatividades que está acontecendo as aulas remotas, sendo que alguns alunos maiores índice de participação, talvez devido o acampamento mais presente dos pais, e outros já com menos interação e participação, talvez por morar em zona rural e fazer sua participação apenas pelo caderno interativo mesmo, tendo em vista a falta de acesso aos recursos tecnológicos.

Nesse novo contexto tecnológico - digital, tudo parece ser mais difícil, porém é preciso ter cuidado para não sobrecarregar as crianças com atividades, tendo em vista que a avaliação nessa fase não tem a intenção de reter o aluno. Pois a mesma é feita de forma diversificada e relativa, sendo através da participação no grupo de WhatsApp, seja pela realização e retorno das atividades propostas no caderno interativo impresso, enfim o que não pode acontecer é deixar de existir essa interação, independentemente do recurso metodológico utilizado pelo professor(a), que no caso das escolas em contextos desta pesquisa essas avaliações são feitas dessas maneiras citadas acima.

No contexto Educacional Infantil, a integração das mídias às práticas pedagógicas tem sido fomentada pelas Diretrizes Curriculares Nacionais para a Educação Infantil, que compõem em sua proposta pedagógica curricular para a Educação Infantil eixos norteadores como brincadeiras e interações que garantem experiências que "[...] possibilitem a utilização de gravadores, projetores, computadores, máquinas fotográficas, e outros recursos tecnológicos e midiáticos" (BRASIL, 2010, p.27). 
As respectivas possibilidades de enfrentamento desafiadoras e ao mesmo tempo inclusiva sobre o novo contexto educacional dada pela Secretaria de Educação Básica quanto à necessidade da abordagem das mídias e das tecnologias na educação infantil torna-se ainda mais importante, tendo em vista que atualmente o público infantil já se encontra manipulando os aparelhos digitais desde muito cedo. Essa iniciativa sugere o reconhecimento da apropriação e interação já existentes, em grande parte, no universo infantil quanto ao uso dos recursos midiáticos e tecnológicos, como televisão, celular, rádio, etc. Pois, como ser social e integrado com o meio em que vivem, as crianças absorvem e apropriam-se dos mais variados conteúdos através desses recursos.

Ressaltamos que o uso da internet, televisão e vídeo na Educação Infantil também pode proporcionar momentos de lazer e aprendizagem. As cores dos desenhos animados e as músicas infantis, remetem a criança para o seu imaginário e a ensina a refletir. Nesse contexto, o cotidiano da criança contemporânea é mediado por diversas informações transmitidas pelos mais variados tipos de mídias, a saber: TV, jornais, rádios, revistas, placas e outdoors nas ruas, sites, web, rede sociais, aplicativos online, escadas rolantes, elevadores, dentre outros agentes alternativos de comunicação, podendo propiciar na criança o desenvolvimento de habilidades múltiplas que não podem ser ignoradas nos âmbitos escolares. O diálogo que é estabelecido por meio das interações sociais entre a criança e, a família, o professor, as outras crianças, e também a mídia, é fundamental para o seu desenvolvimento e a sua formação integral. Sobre esse aspecto, Barbosa (2009, p.31) afirma que:

Os avanços científicos nos mostram a importância das interações sociais para o desenvolvimento das crianças, desde a mais tenra idade, como também evidenciam a relevância da interlocução com as linguagens simbólicas da família, do professor e das demais crianças. A formação das crianças acontece em processos de interação, negociação com os outros ou por oposição a eles.

Contudo, o público Infantil necessita de uma atenção pedagógica especial quanto ao uso das tecnologias, isso implica em aulas mais dinamizadas, tendo um contexto de conteúdos menos tradicionais e mais tecnológicos, com disponibilidades de materiais e recurso digitais essa metodologia aplicada nas respectivas aulas. E para isso, é sabido que todos os sujeitos envolvidos na formação e desenvolvimento destas crianças devem se envolver também nessa tarefa de conhecer melhor as novas linguagens digitalizadas, oriundas dos recursos midiáticos, para, assim, atuarem de forma adequada e enriquecedora para o processo de ensino e aprendizagem do aluno.

Nesse sentido, para melhor atender esses alunos da Educação Infantil, diante do contexto de pandemia no qual estamos inseridos, é preciso que o (a) professor (a), juntamente com os pais, figuras principais nesse processo de mediação, estejam atentos a buscar aprender, se atualizar e se preparar para atuarem com menores dificuldades em relação ao processo de prática e manuseio de ferramentas de apoio didático convencional nas aulas remotas. Entendemos também que, apesar da importância da integração das mídias e dos recursos tecnológicos à educação infantil, as brincadeiras, o dançar, o movimentar-se, o pintar, não podem ser descartados ou substituídos, o professor tem um papel fundamental e indispensável na mesclagem dessas atividades na escola, e nesse momento de pandemia do covid-19 a família também assume esse papel de mediador junto ao público infantil. Corroborando com esse pensamento, temos Moran:

A educação escolar precisa compreender e incorporar mais as novas linguagens, desvendar os seus códigos, dominar as possibilidades de expressão e as possíveis manipulações. É importante educar para usos democráticos, mais progressivos e participativos das tecnologias, que facilitem a evolução dos indivíduos (MORAN, 2013, p.53). 
Diante desse pensamento, e de todo os outros contextualizados e evidenciados nesta pesquisa, é percebido que a Educação Infantil também está sendo inserida nesse processo de inclusão para o uso das novas práticas midiáticas como forma de mediação e criação de possibilidades no ensino remoto para todos os envolvidos.

Percebemos, portanto, que os desafios pautados no uso metodológico e na implementação dos recursos tecnológicos nas aulas não presenciais, são encontrados também na condição docente para efetivar as atividades remotas.

Sem as devidas formações que os qualifiquem para atuar nas aulas de ensino remoto, que se demonstra uma maneira completamente diferente do agir pedagógico. Uma coisa é a aula presencial, modalidade onde todo o conteúdo do curso é exposto por meio de aulas em que os alunos e os professores estão fisicamente no mesmo local e ao mesmo tempo, outra bem diferente é o ensino não presencial que surge como uma interessante saída para momentos emergenciais como o que vivemos, pois viabiliza a continuidade das atividades pedagógicas pela internet, para amenizar os impactos na aprendizagem das crianças e jovens enquanto precisam ficar afastados da escola.

Nos cliques e telas nos quais estão sendo desenvolvidas as aulas remotas, temos alunos, professores e, consequentemente, famílias que acompanham ou estão tentando adentrar a uma realidade desconhecida e angustiante. Aprendendo a como gravar e editar vídeos, tornando o ambiente doméstico o mais próximo possível do espaço escolar, lidando o universo online e mantendo as relações virtuais.

O ambiente escolar interpretado virtualmente por seus alunos possibilita trazer para a sala de aula a realidade deles, desse modo a criança que compõem a Educação Infantil espera que a escola dê continuidade ao seu processo de socialização que começou em casa, e por meio do uso das mídias e tecnologias que já fazem parte do seu cotidiano. Sobre esse aspecto, Moraes e Teruya (2010, p.5) afirmam que "ao assumir uma metodologia colaborativa, o professor deve incorporar o uso da internet como ferramenta auxiliar no processo de ensino e aprendizagem", promovendo assim uma maior integridade e intensidade na relação aluno/docente/escola, além de proporcionar um desenvolvimento significativo no processo de ensino e aprendizagem. Reforçando esse pensamento, citamos Moran:

Com as tecnologias atuais, a escola pode transformar-se em um conjunto de espaços ricos de aprendizagem significativas, presenciais e digitais, que motivem os alunos a aprender ativamente, a pesquisar o tempo todo, a serem proativos, a saber tomar iniciativas e interagir (MORAN, 2013, p.31).

Há alguns anos, as ferramentas de aprendizagem utilizadas pelos docentes na Educação Infantil eram apenas massas, lápis coloridos, brinquedos e brincadeiras, atualmente, entretanto, somados a essas ferramentas estão os recursos tecnológicos e midiáticos, que podem propiciar um ambiente de aprendizagem virtual conectado à realidade das crianças atuais. Numa transmissão enriquecedora, estimulante e colorida, as mídias são utilizadas para ensinar através das mais diversas formas: por imagens, sons, filmes, e falas educativas.

Nessa possibilidade, é relevante dizer que, esse processo acontece na sala de aula como em uma grande brincadeira. Porém esse cenário mudou, é sabido que mesmo em meio a esse contexto de aulas remotas, atividades por caderno de interatividades e o uso mais intensivo das tecnologias 
digitais, é possível sim dar continuidade as essas propostas encadeadas ao processo de ensino e aprendizagem dos discentes.

Apesar de vivermos uma realidade diferente e desafiadora, é possível utilizar vários recursos a favor dessa continuidade de ensino, só que agora de forma remota, e para isso é necessário contar de forma mais constante com o apoio e colaboração da família para que aconteça essas aulas aconteçam. Esse apoio é acompanhado pelos docentes, onde os familiares ou responsáveis tem a devida função de colaborar e auxiliar na mediação dos conteúdos e na realização das atividades propostas, proporcionando assim ao público da Educação Infantil momentos únicos de aprendizagem, em que a sua autonomia poderá se fortalecer e um cidadão crítico e consciente começa a ser gerado dentro dele.

Esses momentos de aprendizagem ocorrem através de leituras e contação de histórias, onde o aluno pode fazer suas reflexões sobre o texto, através de brincadeiras dirigidas com o intuito de trabalhar as coordenações motoras, grossa e fina, onde o docente explica o passo a passo para a realização da mesma, através de confecção e produção de materiais recicláveis, através de conversações sobre o cotidiano de cada um, e diversas outras formas de contextualização e objetivos temáticos trabalhados para a inserção do ensino e aprendizados dos discentes.

Logo, essa relação das mídias deve acontecer de forma a propiciar e fomentar a construção de novas ideias aos alunos. Contudo, não se deve esquecer os mediadores, os docentes, que nesse processo tanto ensinam quanto aprendem, e ousamos dizer, aprendem mais do que ensinam. Contribuindo com este pensamento:

Diferentemente do que alguns educadores e até pais pensavam, o ensino remoto ou as atividades a distância na Educação Básica não serão tão breves e nem se trata de modismo. A educação não presencial deverá perdurar por um período considerável e a educação mediada por tecnologias, como as que estamos presenciando neste momento, deverão se fazer presentes nas escolas e nas aulas a partir de agora, independentemente da pandemia e da crise da Covid-19. O que sabemos de antemão nos leva a um terceiro momento, que é a convivência com o ensino híbrido. Essa parece ser uma tendência inevitável "análise e resolução de problemas, etc. (LIBÂNEO, 2011, p. 70).

\section{CAMINHOS DA PESQUISA}

O objetivo desta pesquisa é de analisar e compreender a realidade que envolve os principais aspectos relativos às contribuições e desafios das mídias e dos recursos tecnológicos na Educação Infantil, tendo como público-alvo os profissionais de educação(docente) os alunos dessa etapa de ensino e os familiares e/ou responsáveis. Trazendo como campo de pesquisa duas escolas de Educação Infantil no Município de Rorainópolis, para tal, buscamos entender o contexto de forma subjetiva e intersubjetiva, com uma abordagem de natureza qualitativa, a partir de uma investigação e análise exploratória de informações sobre o contexto escolar de todos os envolvidos neste processo de ensino remoto.

A análise e interpretação dos dados deram-se por meio de análise exploratória, diante dos apontamentos sobre a relação entre ensino, aulas remotas, metodologias com a utilização de recursos tecnológicos, desafios e aprendizagem. Foi aplicada, no mês de agosto de 2020, uma entrevista com dez perguntas, sendo cinco direcionada aos professores e cinco direcionada aos pais e/ou responsáveis. As mesmas estão discorridas ao longo do contexto abaixo, contando também com a 
utilização do recurso tecnológico mais acessível dentre todos os entrevistados que foi o celular, com o intermédio do aplicativo WhatsApp, que no momento está sendo um dos recursos mais utilizados para comunicação e troca de informações neste tempo de pandemia.

Foram entrevistados seis professores, três em cada uma das escolas e também seis pais, três de cada uma das escolas. As escolas direcionadas a entrevista foram a escola de ensino infantil: Escola Municipal Professor Jean de Sousa Oliveira e a Escola Municipal de Ensino Infantil e Fundamental Ordalha Araújo de Lima. Utilizamos como recurso para a coleta das informações na entrevista: um celular com internet para manter o contato com os entrevistados e cinco perguntas direcionadas aos professores e cinco perguntas direcionadas aos pais, que foras estas - Professor(a)(S):

1) Quais mudanças ocorreram no contexto escolar diante do acontecimento da pandemia do covid$19 ?$

2) Como está funcionando a continuação das aulas remotas estando todos trabalhando de casa?

3) Quais as maiores dificuldade encontradas nessa nova prática de ensino remoto?

4) Como acontece as aulas e como o aluno é avaliado?

5) Como está sendo a participação da família diante desse novo desafio que tem proporcionado o ensino remoto?

Os resultados das respostas foram parecidos, os mesmos pontuaram que as aulas remotas, pautados na necessidade no uso das tecnologias digitais em prol da educação, em especial aos professores, foi um grande desafio, juntamente com a falta de acompanhamento e também falta de habilidades ou talvez acesso a esses meios partindo também da parte dos familiares e/ou responsáveis ao saber não lidar com as ferramentas de apoio em formato digital, o que ocasionou um grande impacto na vida escolar de todos, principalmente dos discentes.

\section{- Pais e/ou responsável(S):}

1) O que mudou na vida cotidiana e escolar sua e de seus filhos com as aulas remotas?

2) Diante da atual situação em que estamos vivendo, você considera importante as atividades das aulas não presenciais/remotas?

3) Você tem encontrado dificuldades para realizar/auxiliar as atividades propostas para seu(sua) filho(a)?

4) Falando sobre as atividades propostas pelo professor, como estão sendo realizadas essas atividades? só virtualmente? Ou tem outras formas de participação?

5) Você tem tempo e disponibilidade para acompanhar seu filho nas atividades propostas? E como tem sido seu contato com o professor?

Já as respostas direcionadas a entrevista com os pais, familiares ou responsáveis, as respostas foram também bastantes incomuns, a maioria disseram que o momento não está sendo fácil, que esta sendo um desafio muito grande ter que acompanhar os filhos nessas aulas por diversos motivos, dentre eles a indisponibilidade de tempo, pois mesmo com a pandemia muitos ainda optam por ir trabalhar para trazer o que comer para casa, a falta de recursos tecnológicos como um celular com 
um bom desempenho, a falta de acesso à internet, outros por não serem alfabetizados , e dentre outros motivos que traz grandes preocupações para os mesmos. A entrevista foi feita somente pelo Whatzapp, não possuindo registros documentais, porém teve grande relevância para a realização desta pesquisa.

Diante desses procedimentos, sobre a metodologia de pesquisa aplicada neste trabalho, nos baseamos em Gil (1999, p.168), que explica que "a interpretação dos dados tem por objetivo a procura do sentido mais amplo da resposta, o que é feito mediante a ligação com outros conhecimentos já assimilados".

\section{RESULTADOS DA PESQUISA}

A pesquisa focou no estudo de três eixos: participação dos alunos e famílias nas atividades propostas, situação do professor e situação referente ao acesso aos meios tecnológicos como recurso mediador nas aulas. Depois de aplicada a entrevista via WhatsApp, somente dois docentes afirmaram contar com a presença da maioria de seus alunos nas interatividades não presenciais. Já quatro dos professores afirmaram que não estão tendo muito retorno na participação dos estudantes em suas aulas.

Já quando direcionamos a pesquisa aos pais, em relação a participação das crianças nas aulas, dois deles afirmaram acompanhar diariamente as interatividades com os filhos, pois não querem que a criança perca o vínculo com a professora(o) e com a escola. Por outro lado, três disseram não saber ler o suficiente para acompanhar o filho no Caderno de Interatividade, outro fator de impacto apontado por esses pais é a falta de tempo. Por fim, a última entrevistada alegou não acompanhar o filho com frequência em suas atividades devido à falta de acesso à internet. Podemos perceber, então, que a falta de tempo, de equipamentos eletrônicos e acesso à internet são os principais motivos para a falta de participação dos pais e a consequente ausência de retorno dos alunos referente às atividades.

Se antes o aluno tinha quatro horas de aulas por dia e um quantitativo de conteúdo das matérias a ser apreendido num certo período, tudo foi transposto para os ambientes virtuais. No entanto, as transposições literais são inviáveis. Essa ânsia por suplantar os prejuízos causados pela situação de isolamento social é a concepção básica do problema das aulas remotas, o que atravessa o modo como as escolas e famílias, via de regra, têm lidado com as atividades que exigem interação remotas, tendo as melhores ou as mais reduzidas condições.

Embasada no contexto disponibilizado pelo jornal pensar a educação em pauta, sobre Aulas Remotas e seus desafios em tempo de pandemia, constata-se que um dos principais desafios é a aquisição de dispositivos (computador, smartphone, tablets, etc.) e o acesso à internet de qualidade revelam a terrível desigualdade social do país. De acordo com o jornal - Pensar a Educação em Pauta o Brasil além de ser um país democrático, é também uma das nações mais injustas, onde poucos detêm a maior parte da riqueza enquanto a maioria da população vive em grande pobreza. (RIBEIRO, S. S. Marcelo; SOUSA, M.M. Clara .10 de jun. de 2020).

Não é de hoje que a educação brasileira precisa se repensar e se reinventar. Existem atitudes e pensamentos que não fazem mais sentido dentro de uma escola, enquanto outros são mais do que urgentes em sua importância. A vida que crianças e adolescentes têm além das escolas precisa estar abarcada não só no ambiente escolar, mais também em todo o seu contexto social. 
Os professores, por sua vez, são obrigados a fazerem conexões entre disciplinas e conteúdos. Foi observado que muitos professores estão dando continuidade no seu trabalho, através de seus planejamentos, das aulas remotas, das correções dos cadernos interativos, mesmo que tenham de se reinventar e aprender a trabalhar com novas tecnologias digitais. Se tornou perceptível, também, a importância da contribuição dos pais para que o processo de aprendizagem tenha continuidade, 0 problema aparece quando notamos que existem pais que, por diversos motivos, não conseguem acompanhar seus filhos de forma frequente, o que resulta numa perda de interesse por parte do aluno, enfraquecendo o vínculo com a escola, o professor(a) e consequentemente com a vontade de aprender. É nesta perspectiva que Moran (2013, p.12) afirma que "a educação formal continua, de maneira geral, organizada de modo previsível, repetitivo, burocrático, pouco atraente, ao mesmo tempo em que a sociedade muda e experimenta desafios mais complexos".

Apesar de todo o embasamento e aparato contemporâneo que defende o uso das mídias e dos recursos tecnológicos como artefatos de educação, predomina, entretanto, na maior parte, a falta de comprometimento de um número não exato de professores e também de algumas famílias em manter esse processo vivo, já que alguns pais mesmo não sabendo ler possuem uma certa facilidade em manusear celulares, o que já ajudaria na participação das crianças nas aulas. Chamamos, por fim, atenção para as famílias que moram em zonas rurais e que não possuem acesso às tecnologias com frequência, realizando então as atividades apenas pelo caderno interativo e a ajuda dos pais. Mesmo assim, são as que mais realizam as interações nos cadernos, mesmo não tendo tantos recursos para o acompanhamento em tempo real das aulas.

\section{CONSIDERAÇÕES FINAIS}

Este trabalho nos permitiu explorar o contexto atual e perceber os desafios no ensino de aulas remotas em meio a pandemia da Covid-19, focalizando em como está tendo continuidade às atividades na rede de Educação Infantil em duas escolas do Município de Rorainópolis-RR. Pudemos perceber que a realidade dos professores e dos alunos quanto ao uso das mídias e dos recursos tecnológicos em suas práxis pedagógicas, têm se dado com grandes dificuldades. Desse modo, notamos que é preciso explorar e conhecer melhor as contribuições das mídias e dos recursos tecnológicos para um bom funcionamento das aulas não presenciais.

Neste novo formato de ensino, destaca-se a interação através de aulas remotas, bem como o uso dos cadernos de interatividade. É sabido desde o início, a grande importância sobre manter a parceria entre escola e família, pois o auxílio dos pais é essencial em todas as etapas de ensino, e principalmente na Educação Infantil, onde as crianças necessitam de adultos que os acompanhem no processo de aprendizagem. Inferimos, portanto, que se torna ainda mais latente o fortalecimento do vínculo entre escola, professor, aluno e família a fim de superarmos os desafios atuais.

Os desafios do momento atual trazem luz à necessidade de uma maior aproximação com recursos tecnológicos bem como a integração das mídias digitais em todas as etapas de ensino, incluindo, a educação infantil, pois as brincadeiras lúdicas, o dançar, o movimentar-se, o pintar, não podem ser descartados ou substituídos, porém, podem ser implementados a uma nova forma de se fazer. 


\section{REFERÊNCIAS}

BRASIL. Base Nacional Comum Curricular (BNCC). Educação é a Base. Brasília, MEC/CONSED/UNDIME, 2017. Disponível em: <http:// basenacionalcomum.mec.gov.br/images/B NCC_publicacao.pdf>. Acesso em: 02 jun. 2017.

BRASIL. Lei no 9.394, de 20 de dezembro de 1996. Estabelece as diretrizes e bases da educação nacional. Diário Oficial da União, Brasília, 23 de dezembro de 1996. Disponível em: <http://www.planalto.gov.br/ccivil_03/leis/L9394.htm>. Acesso em: 26 fev. 2018.

BRASIL. Ministério da Educação. Referencial curricular nacional para a Educação Infantil. (s/p. online). Brasília: MEC, SEB, 1998. BRASIL. Ministério da Educação.

BRASIL, Ministério da Educação e do Desporto. Secretaria de Educação Fundamental. Referencial Curricular Nacional para Educação Infantil. Brasília: MEC/SEF, 1998.

. Ministério da Educação e do Desporto. Secretaria de Educação Fundamental. Parâmetros Nacionais de Qualidade para Educação Infantil, Volume 2. Brasília: MEC/SEC, 2006.

GIL, A.C. Métodos e técnicas de pesquisa social. São Paulo: Atlas, 1999. p. 168.

LIBÂNEO, J.C. Adeus, professor, adeus professora. Pág. 70. São Paulo: Cortez, 2011.

MORAES, S.A., TERUYA, T.K. Paulo Freire e formação do professor na sociedade tecnológica. Págs. 2, 5, 7. UNIOESTE - Universidade Estadual do Oeste do Paraná. Cascavel, PR. 2010.

MORAN, J.M.; MASETTO, M.T.; BEHRENS, M.A. Novas Tecnologias e mediação pedagógica. $21^{a}$ edição revisada e atualizada. Campinas, SP: Papirus, 2013. p. 12, 31 e 53.

PENSAR, a educação. pensar o Brasil. Jornal.1822-2022 - Av. Antônio Carlos, 6627, Pampulha Belo Horizonte - MG - CEP 31270-901 - Faculdade de Educação Sala. 1206.

RIBEIRO, S. S. Marcelo; SOUSA, M.M. Clara. Aulas Remotas e seus desafios em tempo de pandemia. Jornal pensar a educação em pauta. 10 de junho de 2020. Disponível em: $<$ https://pensaraeducacao.com.br/pensaraeducacaoempauta/aulas-remotas-e-seus-desafios-emtempo-de-pandemia> . Acesso em: 24 març. 2021.

Submissão: 15/02/2021

Aceito: 28/04/2021 